\title{
Analysis and Evaluation of the Acrylamide Levels in Some Bread Assortments on the Romanian Market by GC-MS/MS
}

\author{
Mioara Negoita ${ }^{1}$, Enuta Iorga ${ }^{1}$, Alina Adascalului ${ }^{1}$, Luminita Catana ${ }^{1}$, Nastasia Belc ${ }^{1}$, Andreea Stan $^{2}$, Dragos \\ Efstatiade $^{3}$ and Hassan Y. Aboul-Enein ${ }^{4}$ \\ 1. National R \& D Institute for Food Bioresources-IBA Bucharest 021102, Romania \\ 2. University of Agronomic Sciences and Veterinary Medicine-Bucharest, Romania \\ 3. Pro Analysis Systems-Bucharest, Romania \\ 4. Pharmaceutical and Medicinal Chemistry Department, the Pharmaceutical and Drug Industries Research Division, National \\ Research Centre, Dokki, Cairo 12622, Egypt
}

\begin{abstract}
The acrylamide level of some commercial bread assortments have been evaluated. The influence of several flour types on the content of acrylamide in 14 samples of bread, purchased from 5 different suppliers from the market in Bucharest, Romania was studied. For all bread assortments which have been analyzed for acrylamide, the International Commission of Illumination (CIELab) parameters, $\mathrm{L}^{*}, \mathrm{a}^{*}$ and $\mathrm{b}^{*}$ have been also measured in an attempt to correlate the colour of the final product with its acrylamide content. Determination of acrylamide in bread samples was performed by Gas Chromatography coupled with tandem Mass Spectrometry (GC-MS/MS), using isotope dillution calibration after derivatization (bromination). The results revealed that the acrylamide level vary between bread assortments of different brands and bread assortments of same brand, but different lots. In the case of commercial bread samples, the use of whole wheat flours lead to formation of higher quantity in acrylamide $(165.53 \mu \mathrm{g} / \mathrm{kg})$, compared to the use of white wheat flours $(28.02 \mu \mathrm{g} / \mathrm{kg})$.
\end{abstract}

Key words: Acrylamide, flour, bread, GC/MS/MS, CIELab parameters.

\section{Introduction}

Since April 2002, scientists from the National Food Administration in Sweden together with the University of Stockholm reported the presence of acrylamide in a variety of foods based on potatoes and cereals. Basic foods, such as bread, contain acrylamide in very small quantities (level of tens or hundreds of ppb). Nevertheless, it can contribute significantly to the maximum dose in the diet. Internationally research works reported very large variations of the level of acrylamide in foods, from $30 \mu \mathrm{g} / \mathrm{kg}$ in bread up to

Corresponding author: Hassan Y. Aboul-Enein, Ph.D., research fields: environmental, pharmaceutical and biomedical analysis using separation science techniques.

Mioara Negoita, Ph.D., research fields: method development of analysis of food and food product.
$3,500 \mu \mathrm{g} / \mathrm{kg}$ of potato chips [1-3]. Swedish results were quickly confirmed by working groups, comprised of experts of World Health Organization, Food and Agriculture Organization, United Nation Organization, National Centre for Food Safety and Technology, etc.. They have identified and listed research priorities and the potential risk of acrylamide in food on the human health. In February 2005, the Joint FAO/WHO Expert Committee on Food Additives has made an assessment of acrylamide in terms of food safety and concluded that this chemical substance presents risks for human health, being classified by International Agency for Research on Cancer (IARC) as "probably carcinogenic for humans" (group 2A) [4]. Foods with the highest contribution to the intake of acrylamide vary from country to country, depending on national 
food habits and food preparing methods. In general, potato-based products, coffee and bakery products are the major sources of acrylamide. French fries, coffee, bread, biscuits and cereals for breakfast have a contribution of more than $90 \%$ of the intake of acrylamide [5, 6]. Acrylamide levels in bread (in 192 samples) ranged between $5 \mu \mathrm{g} / \mathrm{kg}$ and $1,987 \mu \mathrm{g} / \mathrm{kg}$, with an average of $30 \mu \mathrm{g} / \mathrm{kg}$. Bread can be one of the major contributors to exposure to acrylamide through diet. Baking temperature is high enough to produce acrylamide in product crust [7].

This study includes data on acrylamide content of a category of products (bread), with significant contribution in the daily diet of Romanian consumers. Evaluation of the presence of acrylamide in foods on the Romanian market highlights the risk of consumption of products which contain acrylamide and can constitute a guide for consumers in choosing products with lower acrylamide levels.

\section{Experimental Part}

\subsection{Materials}

In experiments, there were using 14 samples of bread from 5 suppliers (A, B, C, D and E) on the market in Bucharest, Romania, which had different types of flour in their composition, according to the statement on the manufacturer label (Table 1).

\subsection{Methods}

Bread assortments analyzed within the experiments were physically and chemically analyzed, using the following methods:

- moisture determination, according to SR 90:2007;

- lipids content determination, according to SR 91:2007;

- protein content determination, according to SR EN ISO 20483:2007;

Table 1 Commercial bread assortments, purchased from the retail traders on the market in Bucharest, Romania.

\begin{tabular}{|c|c|c|}
\hline Supplier & Assortment name & Used flour type \\
\hline \multirow{6}{*}{ A } & Round bread sliced, $400 \mathrm{~g}$ (code 31$)$ & $\begin{array}{l}\text { Whole wheat flour } \\
\text { Black wheat flour type } 1250,45 \%\end{array}$ \\
\hline & White bread with sage seeds, $500 \mathrm{~g}$ (code 35 ) & White wheat flour type 650 \\
\hline & Hypoglucidic bread, sliced, 500 g (code 36) & $\begin{array}{l}\text { White wheat flour type } 650 \\
\text { Wheat bran } \\
\text { Black wheat flour type } 1250\end{array}$ \\
\hline & Toast bread, $500 \mathrm{~g} / \mathrm{B}$ lot 241 (code 32 ) & \multirow{3}{*}{$\begin{array}{l}\text { Whole wheat flour, } 26 \% \\
\text { Black wheat flour type } 1250 \\
\text { Black wheat flour type } 1000 \\
\text { Malt flour }\end{array}$} \\
\hline & Toast bread, $500 \mathrm{~g} / \mathrm{A}$ lot 242 (code 33) & \\
\hline & Toast bread, $500 \mathrm{~g} / \mathrm{A}$ lot 243 (code 34$)$ & \\
\hline \multirow{5}{*}{ B } & Whole wheat toast, $600 \mathrm{~g}$ (code 37) & $\begin{array}{l}\text { Whole wheat flour, } 60 \% \\
\text { Fermented wheat flour } \\
\text { Soy flour }\end{array}$ \\
\hline & Bread with seeds, $400 \mathrm{~g}(\operatorname{code} 40)$ & $\begin{array}{l}\text { Black wheat flour } \\
\text { Premix (rye flour, white wheat flour, wheat bran, malted wheat flour) }\end{array}$ \\
\hline & Whole wheat bread, $500 \mathrm{~g} /$ lot 22 (code 38$)$ & \multirow{3}{*}{$\begin{array}{l}\text { Whole wheat flour } \\
\text { Fermented wheat flour } \\
\text { Soy flour }\end{array}$} \\
\hline & Whole wheat bread, $500 \mathrm{~g} /$ lot 21 (code 39$)$ & \\
\hline & Whole wheat bread, $500 \mathrm{~g} /$ lot 11 (code 47 ) & \\
\hline $\mathrm{C}$ & Black bread, $700 \mathrm{~g}($ code 41$)$ & Black wheat flour type 1250 \\
\hline $\mathrm{D}$ & Bread with black flour and bran, $600 \mathrm{~g}$ (code 42) & $\begin{array}{l}\text { Black wheat flour } 60 \% \\
\text { White wheat flour } \\
\text { Wheat bran } 3 \% \\
\text { Malt flour }\end{array}$ \\
\hline E & Integral toast, $500 \mathrm{~g}$ (code 43 ) & $\begin{array}{l}\text { Black wheat flour type } 1350 \\
\text { White wheat flour type } 650 \\
\text { Rye flour, soy flour, malt flour, rice flour and malted rye flour }\end{array}$ \\
\hline
\end{tabular}


- ash content determination, according to SR EN 2171:2010;

- salt content determination, according to SR 91:2007;

- acidity determination, according to SR 90:2007;

- sugar content determination, according to SR 91:2007;

- acrylamide determination by GC/MS/MS (internal procedure);

- color measurements (CIELab, L*, a* and $b^{*}$, Hunter lab colorimeter).

\subsection{Determination of Acrylamide}

\subsubsection{Preparation of Bread Samples}

Acrylamide in bread was quantified by GC-MS/MS in Selected Reaction Monitoring mode (SRM) after derivatization, using the preparation methods adapted from Nemato, S. et al. [8], Pittet, A. et al. [9], and Wei-Chih, C. et al. [10] with modifications. Concentration of acrylamide for each bread assortment was expressed in $\mu \mathrm{g} / \mathrm{kg}$ and represents the arithmetic mean of the obtained results by processing at least three parallel samples.

\subsubsection{Standards and Reagents}

Standard solution of native acrylamide, minimum $99 \%$ purity of concentration $1,000 \mu \mathrm{g} / \mathrm{mL}$ in methanol (1,000 ULTRA SCIENTIFIC Analytical Solution), internal standard of labelled acrylamide $\left(1,2,3{ }^{13} \mathrm{C}\right)$. Minimum 99\% purity (+100 ppm hydroquinone) concentration of $1,000 \mu \mathrm{g} / \mathrm{mL}$ in methanol (Cambridge Isotope Laboratories, Inc.) have been used. All reagents were of chromatographic purity.

\subsubsection{Drying and Milling}

Bread samples were dried in oven, at $90{ }^{\circ} \mathrm{C}$ for 120 minutes, coarse milled at Retsch GM 200 mill and then fine milled at ZM 200 ultra-centrifugal mill, through a sieve having a mesh size of $0.2 \mu \mathrm{m}$.

2.3.4 Extraction of the Global Fine Dried Bread Crumbs

About $3 \mathrm{~g}$ of sample have been exactly weighed in a centrifuge vial of $50 \mathrm{~mL}$. The internal standard of labelled acrylamide $(110 \mu \mathrm{L})$, the concentration of 10 $\mu \mathrm{g} / \mathrm{mL}$ was added prior extraction. Acrylamide was extracted in water $\left(30 \mathrm{~mL}, 60{ }^{\circ} \mathrm{C}\right)$, at $\mathrm{pH}=4-5$, deproteinizated with Carrez I and II solutions, centrifuged and the obtained supernatant was passed through glass wool in a conical flask with glass stopper.

\subsubsection{Derivatization}

The supernatant was derivatized with calcined potassium bromide (7.5 g), hydrobromic acid ( $\mathrm{pH} 1-3$ ) and $10 \mathrm{~mL}$ of saturated bromine-water solution (ca. $1.6 \%$ ) at maximum $4{ }^{\circ} \mathrm{C}$, minimum $2 \mathrm{~h}$. After the finishing of the bromination reaction, bromine in excess was removed by adding a few drops of $1 \mathrm{M}$ sodium thiosulfate solution until the yellow color disappeared. 2,3-dibromopropionamide (2,3-DBPA) was extracted with a mixture ethyl acetate: hexane $(4: 1, v / v)$, then the solvent was evaporated and the obtained residue was dissolved in hexane.

\subsubsection{Purification}

Residue dissolved in hexane was purified on a glass column, filled with activated florisil and anhydrous sodium sulfate. 2,3-DBPA derivative was eluted with acetone, then concentrated to dryness and residue was dissolved in $400 \mu \mathrm{L}$ of ethyl acetate and $40 \mu \mathrm{L}$ of triethylamine. The final solution was filtered through a $0.2 \mu \mathrm{m}$ microfilter into an autosampler vial and analyzed by GC-MS/MS in SRM mode.

\subsubsection{Preparation of Calibration Solutions}

A blank solution and 7 calibration levels have been prepared in eight conical flasks of $250 \mathrm{~mL}$. The concentration range was: $0.1-7.5 \mathrm{mg} / \mathrm{L}$. In each flask $100 \mathrm{~mL}$ ultrapure water, $110 \mu \mathrm{L}$ internal standard of $\left({ }^{13} \mathrm{C}_{3}\right)$ acrylamide $(10 \mu \mathrm{g} / \mathrm{mL})$ and working solution I of acrylamide $(10 \mu \mathrm{g} / \mathrm{mL}): 0 \mu \mathrm{L}, 11 \mu \mathrm{L}, 27.5 \mu \mathrm{L}, 55$ $\mu \mathrm{L}, 110 \mu \mathrm{L}, 275 \mu \mathrm{L}, 550 \mu \mathrm{L}$ and $825 \mu \mathrm{L}$ have been respectively added. These solutions were identically derivatized as in the steps described at the derivatization of bread samples (without purification) and the final residue was dissolved with $1,000 \mu \mathrm{L}$ ethyl acetate and $100 \mu \mathrm{L}$ triethylamine. 


\subsubsection{GC-MS/MS—SRM Analysis}

Extracts of the samples and the derivatized calibration standards were analyzed using a gas chromatograph TRACE GC ULTRA coupled with a triple quadrupole mass spectrometer, TSQ Quantum XLS (Thermo Fisher Scientific, USA). Analyses were performed in electron ionization, positive ion mode $\left(\mathrm{EI}^{+}\right)$in Selective Reaction Monitoring-SRM acquisition mode. A low bleed column of $30 \mathrm{~m}$ length $\times 0.25 \mathrm{~mm}$ internal diameter and $0.25 \mu \mathrm{m}$ stationary phase film thickness, with polyethylene-glycol stationary phase (Trace GOLD ${ }^{\mathrm{TM}}$ TG-Wax MS Thermo Fisher Scientific, USA) and as mobile phase, helium of minimum 99.9995\% (5.0) purity, with a constant flow rate of $1.6 \mathrm{~mL} / \mathrm{min}$ was used. Argon was used as CID collision gas ( $1 \mathrm{~m}$ Torr). $1 \mu \mathrm{L}$ of sample has been injected in a split/splitless injector (Right PTV) using a TriPlus AS autosampler (Thermo Fisher Scientific, USA) in split mode, split ratio 1:10 and temperature of $220{ }^{\circ} \mathrm{C}$. Under these conditions, retention time of the native acrylamide and the internal standard was $10.65 \mathrm{~min} \pm 30 \mathrm{sec}$. Acrylamide and internal standard of acrylamide were identified by ion fragments, corresponding to derivatized ions, 2-BPA and 2-BP $\left({ }^{13} \mathrm{C}_{3}\right)$ A. Collision of precursor ions with $\mathrm{m} / \mathrm{z} 151$ and $\mathrm{m} / \mathrm{z} 154$ led to the formation of product ions with $\mathrm{m} / \mathrm{z}$ 70 (2-BPA) and $73\left(2-\mathrm{BP}\left({ }^{13} \mathrm{C}_{3}\right) \mathrm{A}\right)$, which were used to quantify acrylamide. The calculation of acrylamide concentration in test samples was based on the ratio of the peak area corresponding to the product ions with $\mathrm{m} / \mathrm{z} 70$ for 2-BPA and $\mathrm{m} / \mathrm{z} 73$ for 2-BP $\left({ }^{13} \mathrm{C}_{3}\right) \mathrm{A}$.

\section{Method Performance Evaluation}

\subsection{Repeatability}

Ten injections of a standard solution of $0.1 \mathrm{mg} / \mathrm{L}$ of acrylamide have been injected. Repeatability obtained was $1.73 \%$ RSD for the corrected areas (area of 2-BPA/area of 2-BP $\left({ }^{13} \mathrm{C}_{3}\right) \mathrm{A}$ ). Ten injections of a standard solution of 7,500 $\mathrm{mg} / \mathrm{L}$ of acrylamide have been injected. Repeatability obtained was $0.92 \%$ RSD for the corrected areas (area of 2-BPA/area of
2-BP $\left.\left({ }^{13} \mathrm{C}_{3}\right) \mathrm{A}\right)$.

\subsection{Linearity}

A linear calibration curve was calculated for injections of $0.1 \mathrm{mg} / \mathrm{L}, 0.25 \mathrm{mg} / \mathrm{L}, 0.5 \mathrm{mg} / \mathrm{L}, 1 \mathrm{mg} / \mathrm{L}$, $2.5 \mathrm{mg} / \mathrm{L}, 5 \mathrm{mg} / \mathrm{L}$ and $7.5 \mathrm{mg} / \mathrm{L}$ of acrylamide (about 3 orders of magnitude). The correlation coefficient obtained was $\mathrm{r}^{2}=1.0$, the slope was 1.0517 and the intercept was 0.0106 .

\subsection{LOD and $L O Q$}

They have been evaluated from the calibration curve using the formulas: $\mathrm{LOD}=3.3 \mathrm{\sigma} / \mathrm{slope}$ and LOQ $=10 \sigma /$ slope. The obtained LOD $=0.030 \mathrm{mg} / \mathrm{L}$ of acrylamide and LOQ $=0.095 \mathrm{mg} / \mathrm{L}$ of acrylamide, which significantly exceeds the Commission Recommendation values, making this method appropriate for acrylamide analysis in bakery products.

\subsection{Color Measurements of Bread Samples}

Measurement of color parameters of dried bread crumb was performed at room temperature, with HunterLab colorimeter, using Universal Software V4.01 Miniscan XE Plus, with recording of the CIELab parameters, $\mathrm{L}^{*}, \mathrm{a}^{*}$ and $\mathrm{b}^{*}$. In this color space, value $L^{*}$ represents Lightness ( 0 is black, and 100 is white), value $a^{*}$ represents red-green coordinate (a positive $\mathrm{a}^{*}$ value indicates redness and a negative $\mathrm{a}^{*}$ value indicates greenness) and value $b^{*}$ represents yellow-blue coordinate (a positive $b^{*}$ value indicates yellowness and a negative $b^{*}$ value indicates blueness). Total color difference for two samples (control and standard), $\Delta \mathrm{E}^{*}$ was calculated with equation: $\Delta \mathrm{E}^{*}=\left[\left(\Delta \mathrm{L}^{*}\right)^{2}+\left(\Delta \mathrm{a}^{*}\right)^{2}+\left(\Delta \mathrm{b}^{*}\right)^{2}\right]^{1 / 2}$. For each sample, there were made measurements in 10 different points, then achieves their averages.

\section{Results and Discussions}

Several dried bread crumbs of the commercial bread assortments obtained from different types of flours are depicted in Fig. 1. 

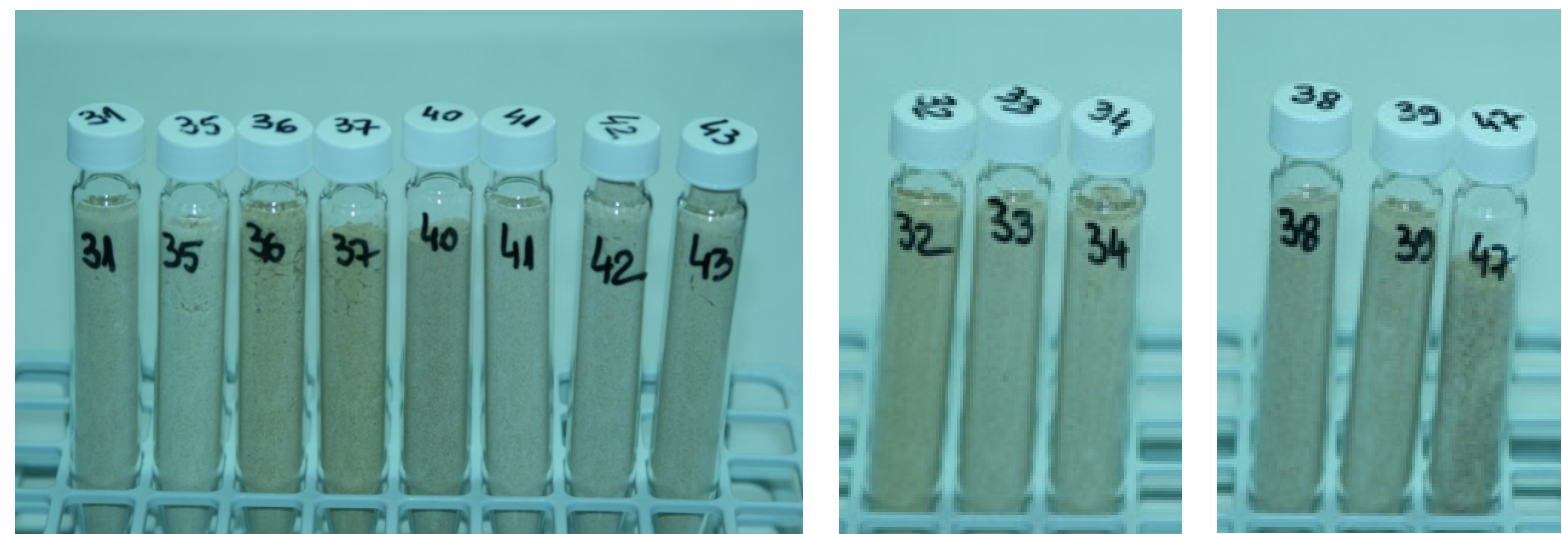

Code 31-Round bread sliced; Code 35-White bread with sage seeds; Code 36-Hypoglucidic bread, sliced; Code 37-Whole wheat toast; Code 40-Bread with seeds; Code 41-Bread with black flour and bran; Code 43-Integral toast; Code 32-Toast bread, lot no. 241; Code 33-Toast bread, lot no. 242; Code 34-Toast bread, lot no. 243; Code 38-Whole wheat bread, lot no. 22; Code 39-Whole wheat bread, lot no. 21; Code 47-Whole wheat bread, lot no. 11.

Fig. 1 Dried bread crumb of the commercial bread assortments.

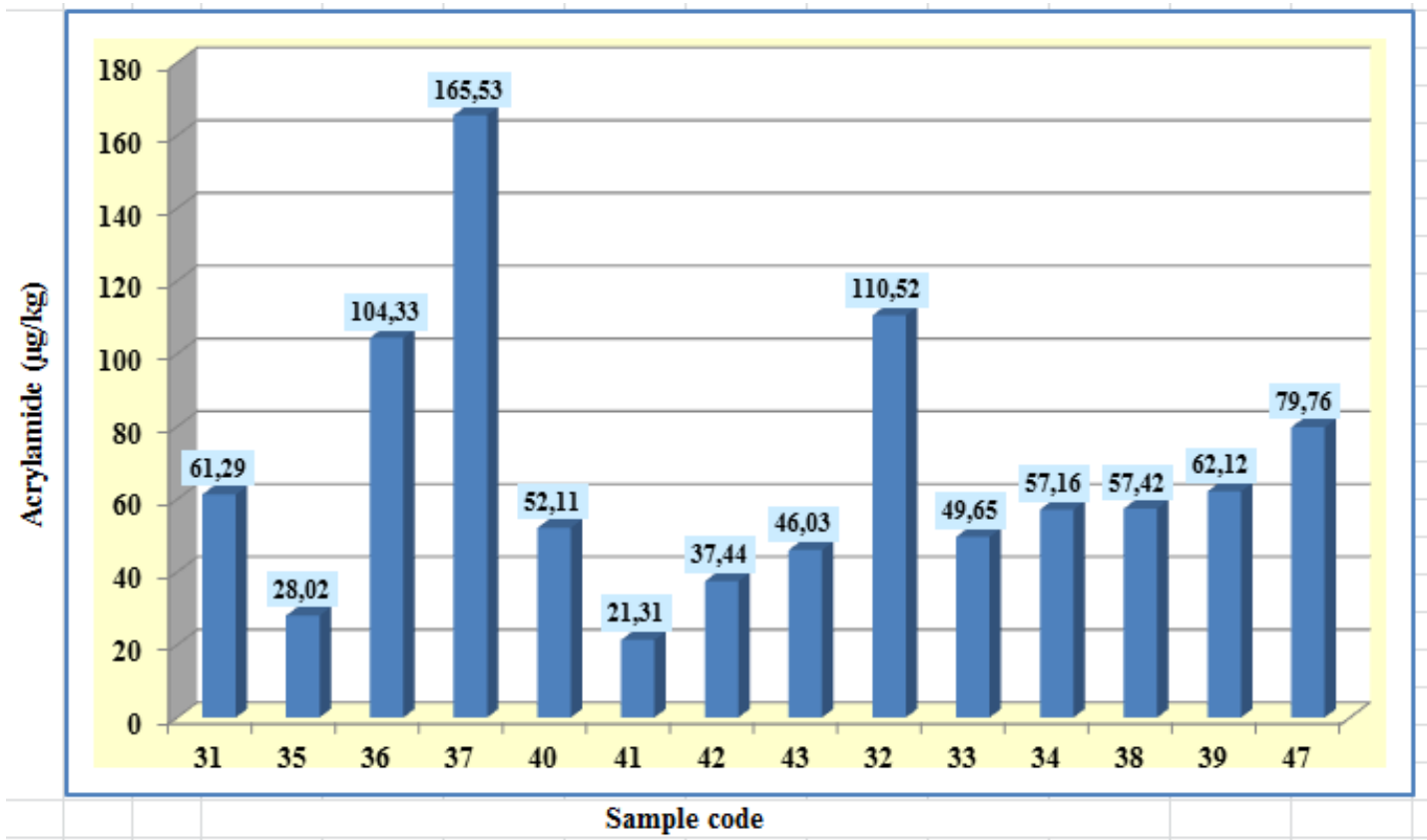

Fig. 2 Variation of acrylamide level of the commercial bread assortments.

The highest level of acrylamide was obtained from the bread assortment, "Whole wheat toast" (code 37), $165.53 \mu \mathrm{g} / \mathrm{kg}$, having in the formulation recipe $60 \%$ Whole wheat flour as shown in Fig. 2. The lower levels of acrylamide were obtained from the bread assortments which have in composition black flour type 1250, "Black bread" (code 41), $21.31 \mu \mathrm{g} / \mathrm{kg}$ and white wheat flour type 650 and "White bread with sage seeds" (code 35), $28.02 \mu \mathrm{g} / \mathrm{kg}$.

The European Commission issued on the basis of the EFSA monitoring data from 2007-2012. The Commission Recommendation on 8 November 2013 (2013/647/EU), investigate into the levels of acrylamide in food, in which the indicative acrylamide value for soft bread-wheat based bread is $80 \mu \mathrm{g} / \mathrm{kg}$, and for soft bread other than wheat based bread is 150 $\mu \mathrm{g} / \mathrm{kg}$ [11]. According to this recommendation, concentrations in acrylamide higher than $80 \mu \mathrm{g} / \mathrm{kg}$ were obtained from the following commercial bread assortments taken into study: 
- "Whole wheat toast" (code 37), $165.53 \mu \mathrm{g} / \mathrm{kg}$;

- "Toast bread", lot no. 241 (code 32), 110.52 $\mu \mathrm{g} / \mathrm{kg}$;

- "Hypoglucidic bread, sliced" (code 36), 104.33 $\mu \mathrm{g} / \mathrm{kg}$.

Concentrations in acrylamide lower than $80 \mu \mathrm{g} / \mathrm{kg}$ were obtained from the following assortments:

- "Black bread" (code 41), $21.31 \mu \mathrm{g} / \mathrm{kg}$;

- "White bread with sage seeds" (code 35), 28.02 $\mu \mathrm{g} / \mathrm{kg}$;

- "Bread with black flour and bran" (code 42), $37.44 \mu \mathrm{g} / \mathrm{kg}$;

- "Integral toast" (code 43), $46.03 \mu \mathrm{g} / \mathrm{kg}$;

- "Toast bread", lot no. 242 (code 33), 49.65 $\mu \mathrm{g} / \mathrm{kg}$;

- "Bread with seeds" (code 40), $52.11 \mu \mathrm{g} / \mathrm{kg}$;

- "Toast bread", lot no. 243 (code 34), 57.16 $\mu \mathrm{g} / \mathrm{kg}$;

- "Whole wheat bread", lot no. 22 (code 38), 57.42 $\mu \mathrm{g} / \mathrm{kg}$;

- "Round bread sliced" (code 31), $61.29 \mu \mathrm{g} / \mathrm{kg}$;

- "Whole wheat bread", lot no. 21 (code 39), 62.12 $\mu \mathrm{g} / \mathrm{kg}$;

- "Whole wheat bread", lot no. 11 (code 47), 79.76 $\mu \mathrm{g} / \mathrm{kg}$.

The acrylamide level in the commercial bread assortments, type toast (Fig. 3), from different suppliers, "Integral toast" (code 43), supplier E and "Whole wheat toast" (code 37), supplier B was compared. The results indicated that sample code 37, in which predominates Whole wheat flour has a level of acrylamide higher than sample code 43 , obtained from black wheat flour type 1350, white wheat flour type 650 , rye flour, soy flour, malt flour, rice flour and malted rye flour. The use of Whole wheat flour in a product brings, on one hand, a nutritional intake to finished product, but, on the other hand, provides a greater level of acrylamide (code 37). Replacing in the formulation recipe of the Whole wheat flour (code 37) with black wheat flour type 1350, white wheat flour type 650 , rye flour, rice flour (code 43 ), results in

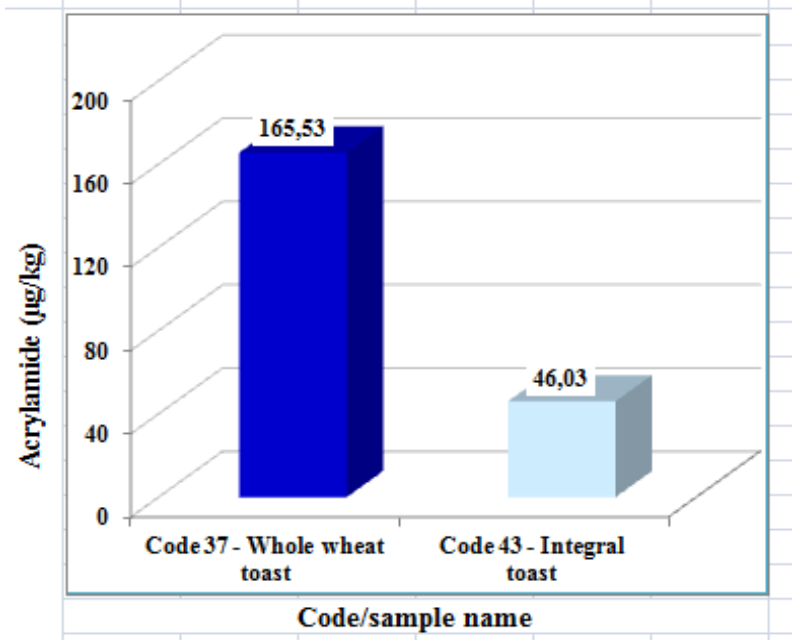

Fig. 3 Variation of acrylamide level in commercial bread assortments, type toast.

formation of a smaller amounts of acrylamide levels of about 3.6 times. According to the literature $(\mathrm{CAC} / \mathrm{RCP}$ 67-2009), rye flour, rice flour contain smaller amounts of asparagine (rye $319-880 \mathrm{mg} / \mathrm{kg}$ and rice $15-25$ $\mathrm{mg} / \mathrm{kg}$ ) compared to whole wheat flour containing greater amounts of asparagine $(2,200 \mathrm{mg} / \mathrm{kg})$ [12]

Considering as standard sample code 43 (lower acrylamide concentration and greater luminance), it observes that sample code 37 is darker and has a content of acrylamide higher than standard, with a color difference, $\Delta \mathrm{E}^{*}=6.68$ (Fig. 4).

Commercial bread assortments in which predominate white wheat flour type 650 (Fig. 5), from the same supplier (A), "White bread with sage seeds" (code 35) and "Hypoglucidic bread, sliced" (code 36) were compared. The results indicated that the sample code 35 , containing $100 \%$ white wheat flour type 650 , had a lower acrylamide level than the sample code 36 , containing besides white wheat flour type 650 and wheat bran as well as black wheat flour type 1250 .

Also, replacement of a portion of quantity of white wheat flour with wheat bran and black wheat flour type 1250 (code 36), causes, on the one hand, increase of nutritional value, but, on the other hand, increas of the acrylamide level of 3.7 times, compared with use of $100 \%$ of white wheat flour (code 35). Also, the use in the formulation recipe of sage seeds could lead to the 

on the Romanian Market by GC-MS/MS

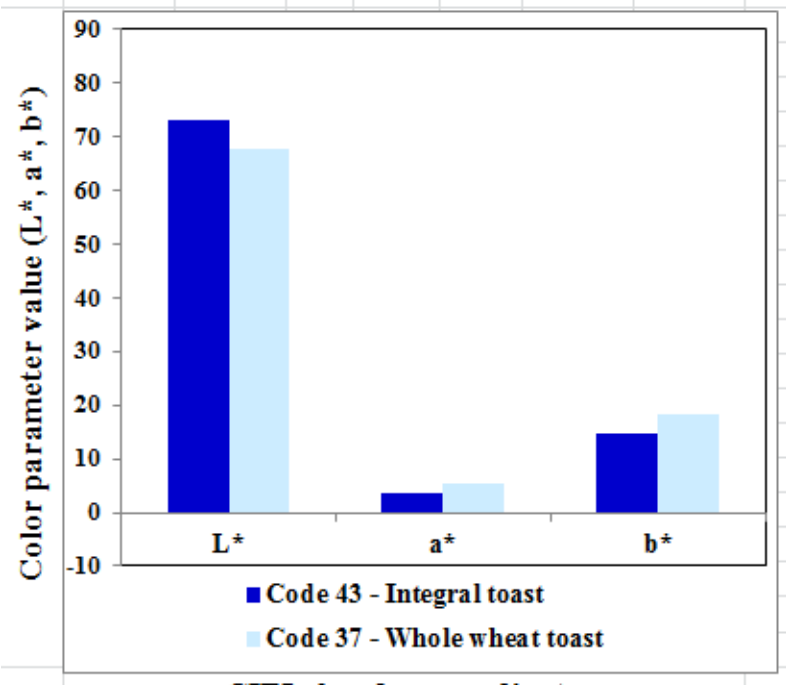

CIELab color coordinate

Fig. 4 CIELab parameters of the commercial bread assortments, type toast.

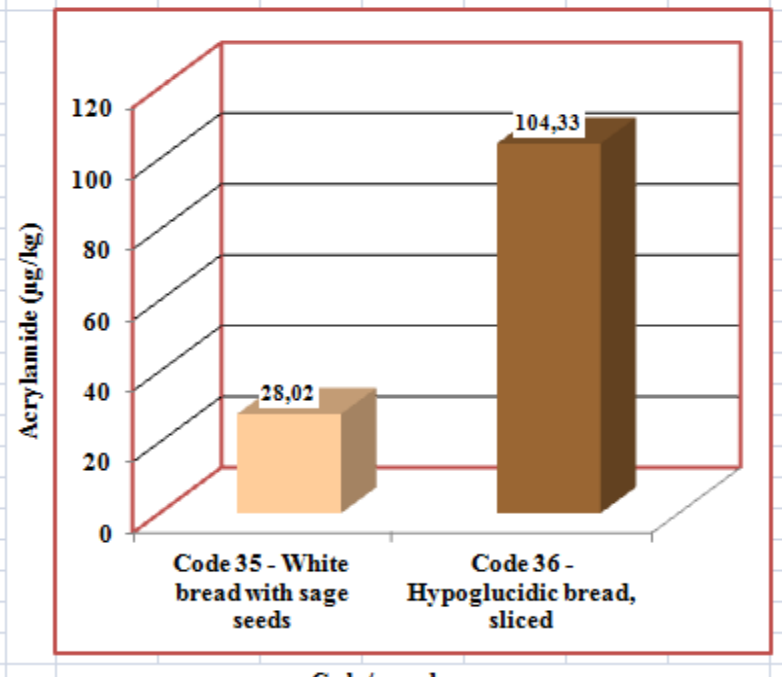

Fig. 5 Variation of acrylamide level in commercial bread assortments (predominates white wheat flour type 650).

reduction of acrylamide level (further studies necessary). Sage seeds can act as a powerful antioxidant, having a positive effect in reducing acrylamide, blocking oxidation of acrolein to a certain level.

Considering as standard sample code 35 (lower acrylamide concentration and greater luminance), in term of color difference, $\Delta \mathrm{E}^{*}=9.13$, sample code 36 is darker and has acrylamide content higher than standard (Fig. 6).

The level of acrylamide formed in commercial bread assortments tested in this study was found to high in black wheat flour as shown in Fig. 7:

- "Round bread sliced" (code 31), supplier A;

- "Bread with seeds" (code 40), supplier B;

- "Black bread" (code 41), supplier C;

- "Bread with black flour and bran" (code 42), supplier D.

It is noted that sample code 41, obtained from $100 \%$ black wheat flour, had the lowest acrylamide content compared to other bread assortments (code 42, 40 and 31), in which also used other types of flour (Table 1).

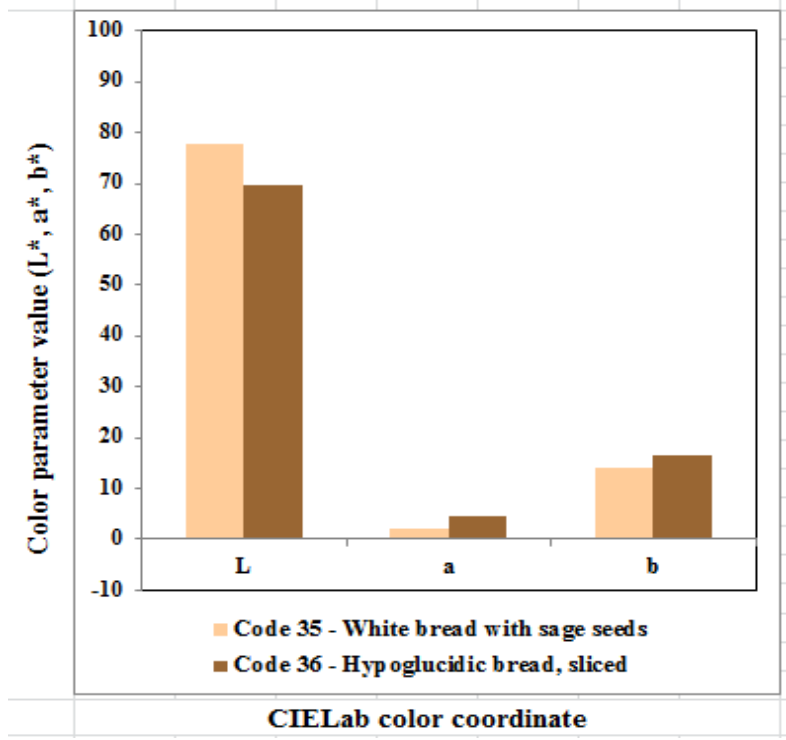

Fig. 6 CIELab parameters of the commercial bread assortments (predominates white wheat flour type 650).

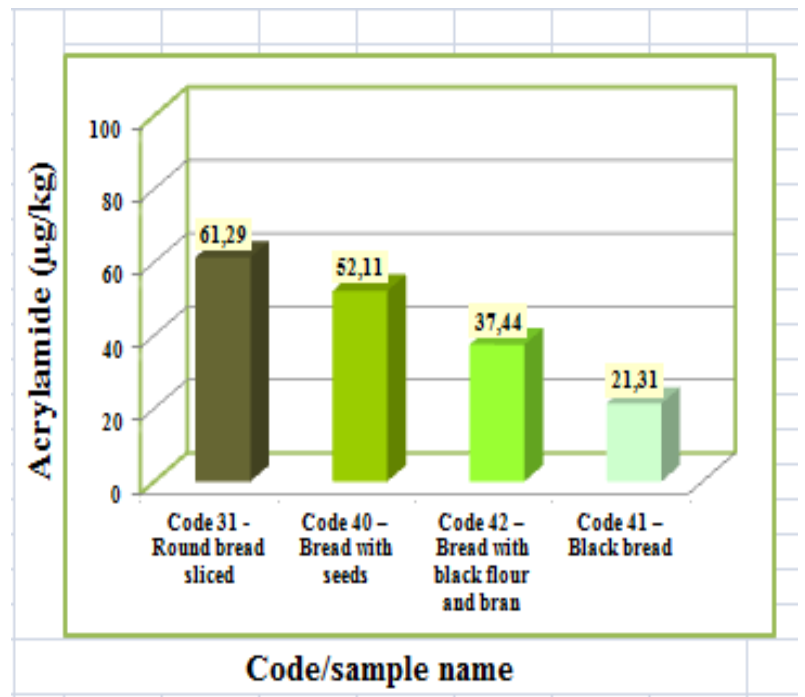

Fig. 7 Variation of acrylamide level in commercial bread assortments (predominates black wheat flour). 


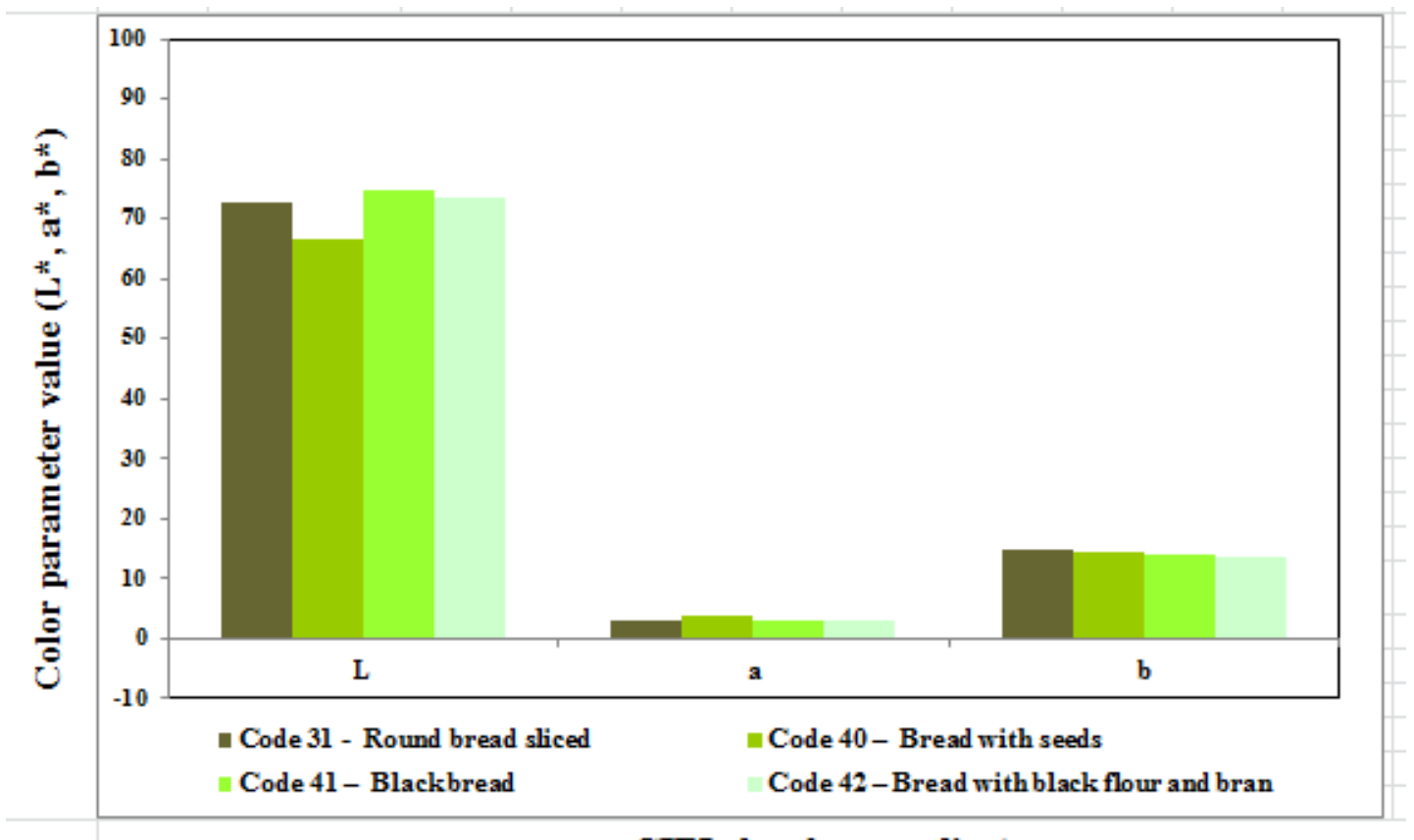

CIELab color coordinate

Fig. 8 CIELab parameters of the commercial bread assortments (predominates in black wheat flour).

Comparing sample "Bread with black flour and bran" (code 42) with sample "Black bread" (code 41), it is noted that in sample code 42 , the replacement of $40 \%$ of black wheat flour with white wheat flour, $3 \%$ wheat bran and malt flour, resulted in an increase of $75.69 \%$ (1.76 times higher) of acrylamide content compared with sample code 41 , in which used $100 \%$ black wheat flour (Fig. 7). Sample code 42 is darker and has a higher acrylamide content than sample code 41, and therefore considered as standard. Color difference between sample and standard is $\Delta \mathrm{E}^{*}=1.26$ (Fig. 8).

In Fig. 7, it indicates that when the sample "Bread with seeds" (code 40) replaced the formulation recipe of an amount of black wheat flour by a premix consisting of rye flour, white wheat flour, wheat bran and malted wheat flour resulted in an increase of $144.53 \%$ (2.45 times higher) of acrylamide content than the sample "Black bread" (code 41), which consisted of $100 \%$ black wheat flour. Considering as standard sample code 41 (lower acrylamide content, greater luminance), in terms of color difference, $\Delta \mathrm{E}^{*}$ $=8.16$, sample code 40 is darker and has an acrylamide content higher than the standard, code 41 (Fig. 8).

Comparing sample "Round bread sliced" (code 31) with sample "Black bread" (code 41), it was observed that (Fig. 7) at sample code 31, replacement in the formulation recipe of $55 \%$ of quantity of black wheat flour with whole wheat flour resulted in an increase of $187.61 \%$ (2.87 times higher) of acrylamide content than the sample code 41 , which consisted of $100 \%$ black wheat flour. In terms of color, after calculations, sample code 31 is darker and has a higher acrylamide content than the sample code 41 , considered as standard, having a color difference, $\Delta \mathrm{E}^{*}=2.24$ (Fig. 8).

Analyzing 3 lots of 2 bread assortments from two suppliers (A, B), acrylamide level varied from batch to batch. Thus, in case of supplier A, the level of acrylamide found in the product "Toast bread", lot 241, lot 242 and lot 243, ranged between $49.65-110.52 \mu \mathrm{g} / \mathrm{kg}$. The highest value of acrylamide concentration was obtained at lot $241(110.52 \mu \mathrm{g} / \mathrm{kg})$, being of 2.22 times higher than the lowest value obtained for lot $242(49.65 \mu \mathrm{g} / \mathrm{kg})$ (Fig. 9).

Analyzing the lots of product from the supplier A, 

on the Romanian Market by GC-MS/MS

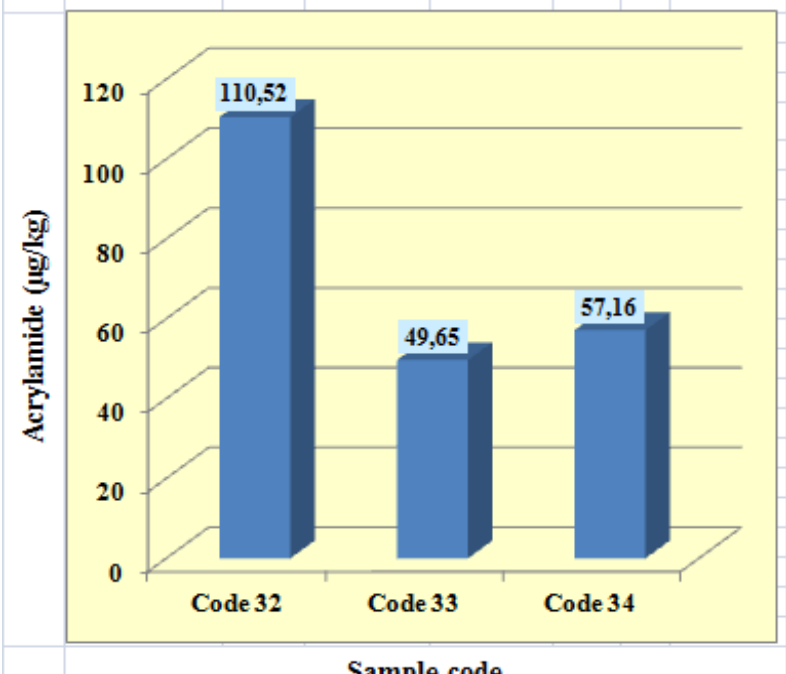

Fig. 9 Variation of acrylamide level of 3 different bread lots of the same supplier A.

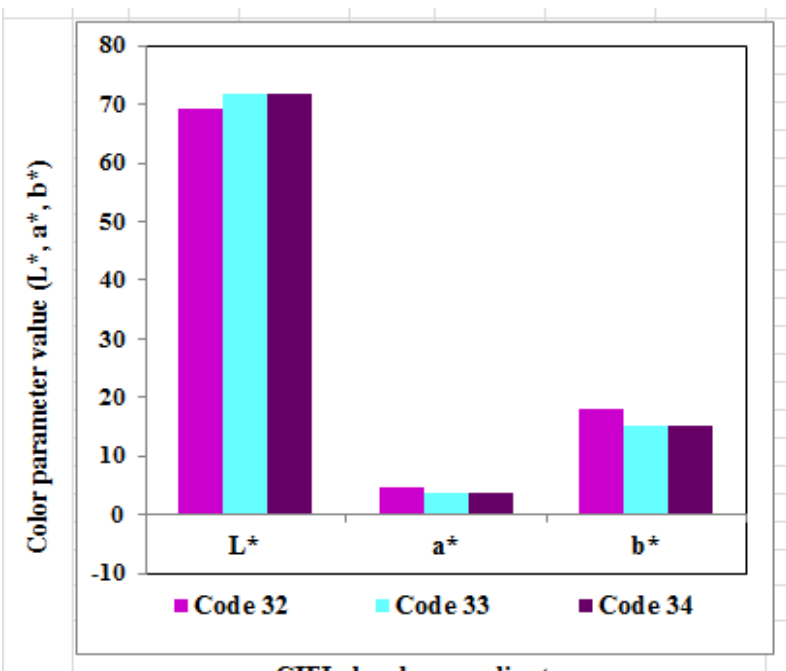

Fig. 10 CIELab parameters of the product lots from the supplier A.

in terms of acrylamide level with color parameter, $\mathrm{L}^{*}$, one can conclude that a darker color of bread (code $32 /$ lot $\left.241, L^{*}=69.21\right)$ contains a higher acrylamide level $(110.52 \mu \mathrm{g} / \mathrm{kg})$, while a lighter color of bread (code $33 /$ lot A $242, L^{*}=71.77$ ) contains a lower acrylamide level (49.65 $\mu \mathrm{g} / \mathrm{kg}$ ) (Fig. 10).

In case of lots from supplier B, acrylamide level ranged between $57.42-79.76 \mu \mathrm{g} / \mathrm{kg}$ (Fig. 11). The highest value of acrylamide concentration was obtained at lot 11 (code 47), being of 1.38 times higher than the lower value of acrylamide concentration at lot 22 (code 38). In the case of those
3 lots (code 38, 39 and 47) of the same product, the same supplier (B), differences between the values of acrylamide level were quite small compared to differences obtained between those 3 lots of product from the supplier A.

Small differences between the acrylamide level of those 3 lots, supplier B are correlated with the quite small differences of color parameters which have very close values ( $L^{*}=69,67.68$ and 68.34) (Fig. 12). Data obtained showed that the 3 lots products of supplier A contain significant higher levels of acrylamide (average $72.44 \mu \mathrm{g} / \mathrm{kg}$ ) compared to the 3 lots product obtained from supplier B (average 66.44 $\mu \mathrm{g} / \mathrm{kg}$ ), taking into consideration that both products from those 2 suppliers are made from the same flour type namely whole wheat flour.

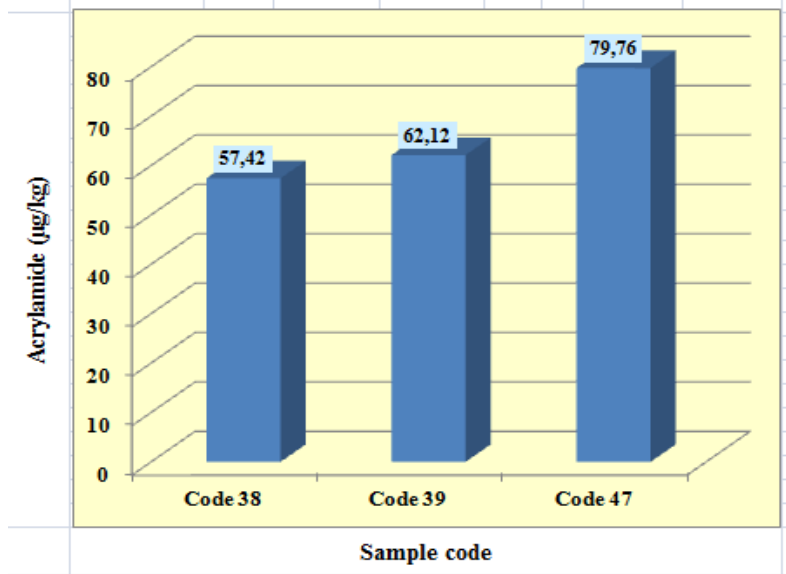

Fig. 11 Variation of acrylamide level of 3 different bread lots of the same supplier $B$.

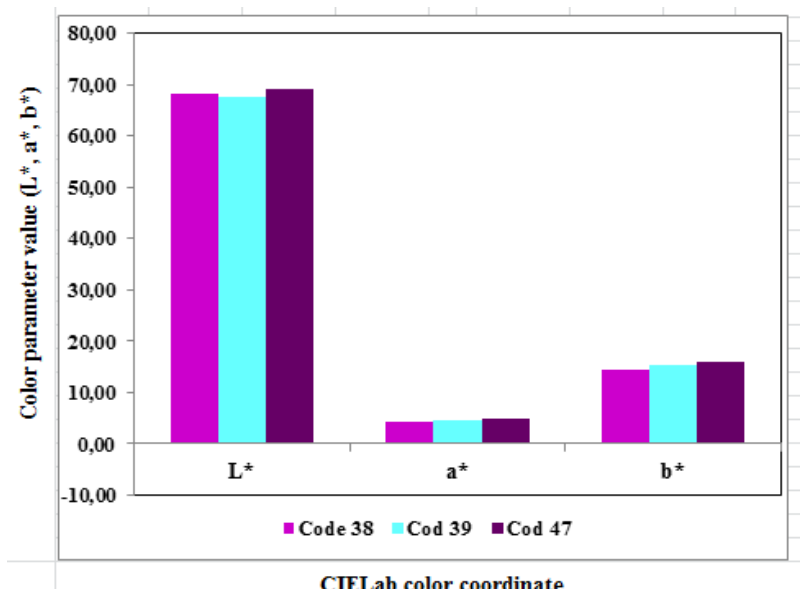

Fig. 12 CIELab parameters of the product lots from the supplier B. 


\section{Conclusions}

In this investigation, several bread assortments were analysed for the acrylamide levels. The results indicated that the bread which is made of whole wheat flour had the highest level of acrylamide while the bread assortments made with black wheat flour and white wheat flour in composition had the lowest acrylamide concentrations. In terms of color parameters, it was found that darker samples (lower luminance) had higher content in acrylamide than lighter samples (greater luminance) which had lower acrylamide content. Periodic analysis of acrylamide, in the same bread product (same manufacturing process, same supplier) but different lots showed a difference in acrylamide concentration, i.e. there was a batch to batch difference in the acrylamide level.

Other physical or chemical parameters of the analyzed samples (moisture, lipids content, protein content, ash content, salt content, acidity, sugar content and crude fiber) could not be unequivocally correlated to acrylamide content and further studies are in progress.

Evaluation of acrylamide level for a product category with a significant contribution in the daily diet of Romanian consumers is important for consumers safety and protection. It is recommended that the economic agents in the field have to examine carefully technologies and manufacturing recipes and apply optimal methods for reducing acrylamide level in the products to guarantee consumers safety.

\section{Acknowledgements}

This study was supported by the Ministry of National Education-State Authority for Scientific Research, Technological Development and Innovation, by "Nucleu" Program PN 12 48, contract 48 N/2012. The authors declare no conflict of interest.

\section{References}

[1] Swedish National Food Administration. 2002. "Information about Acrylamide in Food." Accessed January 12. 2005. http//www.slv.se.

[2] Report of Joint FAO/WHO Consultation WHO Headquarters, Geneva, Switzerland 25-27 June 2002.

[3] Tareke, E., Rydberg, P., Karlsson, P., Eriksson, S., and Tornqvist, M. 2002. "Analysis of Acrylamide, a Carcinogen Formed in Heated Foodstuffs." Journal of Agricultural and Food Chemistry 50: 4998-5006.

[4] Joint FAO/WHO Expert Committee on Food Additives, (FAO/WHO). 2006. Evaluation of Certain Food Contaminants. WHO Technical reports.

[5] Svensson, K., Abramsson, L., Becker, W., Glynn, A., Hellenas, K. E., and Lind, Y. et al. 2003. "Dietary Intake of Acrylamide in Sweden." Food and Chemical Toxicology 41: 1581-1586.

[6] Elbashir, A. A., Omar, M. M. A., Schmitz, O. J., and Aboul-Enein, H. Y. 2014. "Acrylamide Analysis in Food by Liquid and Gas Chromatographic Methods." Critical Reviews in Analytical Chemistry 44: 107-141.

[7] Senyuva, H., and Gokmen, V. 2005. "Survey of Acrylamide in Turkish Foods by an in-House Validated LC-MS Method." Food Additives and Contaminants 22: 204-209.

[8] Nemato, S., Takatsuki, S., Sasaki, K., and Maittani, T. 2002. "Determination of Acrylamide in Foods by GC/MS Using ${ }^{13} \mathrm{C}$-Labeled Acrylamide as an Internal Standard." Journal of Food Hygienic Society of Japan 43: 371-376.

[9] Pittet, A., Perisset, A., and Oberson, J. M. 2004. "Trace Level Determination in Cereal-Based Foods by Gas Chromatography-Mass Spectrometry." Journal of Chromatography A 1035: 123-130.

[10] Wei-Chih, C., Shun-Wen, H., Shin-Shou, C., Sun-Hwang, L., Lu, T. J., and Yeh, A. I. 2006. "Determination of Acrylamide in Chinese Foods by GC-Ion Trap MS Using 2-Bromopropenamide and 2-Bromopropenamide- ${ }^{13} \mathrm{C}_{3}$." $\mathrm{J}$. Food and Drug Analysis 4 (2) 207-214.

[11] Commission Recommendation 2013/647/EU of 8.11.2013: On investigations into the Levels of Acrylamide in Food.

[12] Codex Alimentarius Commission. 2009. "Code of Practice for the Reduction of Acrylamide in Foods." Accessed April 10, 2014. http//www.codexalimentarius.org/input/download/standar ds/11258/CXP_067e.pdf. 